\title{
Ação social responsável: práticas de letramento científico e matemático nos anos iniciais do ensino fundamental
}

Adriano Santos de Mesquita drykosantos@gmail.com orcid.org/0000-0002-4322-4560 Programa de Pós-Graduação em Educação Científica e Tecnológica (PPGECT), Universidade Federal de Santa Catarina, Florianópolis, Santa Catarina, Brasil

\begin{abstract}
RESUMO
Agir com responsabilidade social é um dos objetivos desejados aos alunos dos anos iniciais do Ensino Fundamental. Fomentar, por meio do ensino de Ciências e Matemática, tomadas de decisão conscientes objetivando o exercício da cidadania, permite às crianças atuarem de forma expressiva nos diversos contextos sociais dos quais fazem parte. Nesse âmbito, o presente estudo, de cunho qualitativo, na perspectiva da narrativa autobiográfica, tem como objetivo apresentar e analisar aspectos relativos à ação social responsável a partir de práticas de letramento científico e matemático desenvolvidas com uma turma de quinto ano do Ensino Fundamental na cidade de Belém - PA. Para a produção do material empírico utilizo uma atividade interdisciplinar, adotada por mim, para criar um ambiente favorável às práticas de ação social responsável sob a ótica do letramento científico e matemático, além de rodas de conversa sobre as temáticas propostas, atividades escritas dos alunos e meus registros em diário de campo. Os resultados salientam que, ao proporcionar atividades de letramento científico e matemático em sala de aula, os alunos tendem a se posicionar com responsabilidade social em diferentes contextos da vida, o que Ihes incita a tomadas de decisão consciente e ao efetivo exercício da cidadania.
\end{abstract}

PALAVRAS-CHAVE: Letramento científico e matemático. Narrativa autobibliográfica. Responsabilidade social. 


\section{INTRODUÇÃO}

Nas últimas décadas, em nosso país, diversos autores (SANTOS; MORTIMER, 2001; SASSERON; MACHADO, 2017; CUNHA, 2018; AGUIAR; ORTIGÃO, 2012; GALVÃO; NACARATO, 2013) têm se dedicado ao estudo do letramento científico e matemático como estratégia para melhorar o desempenho dos alunos e suas habilidades em saber relacionar o conhecimento à realidade vivida. Nesse contexto, entendo que, agir com responsabilidade social é um dos objetivos desejados aos alunos dos anos iniciais do Ensino Fundamental. Fomentar, por meio do ensino de Ciências e Matemática, tomadas de decisão conscientes objetivando o exercício da cidadania, permite às crianças atuarem de forma expressiva nos diversos contextos sociais dos quais fazem parte.

À escola, a meu ver, inserida na estrutura de reprodução das relações sociais, tem se delegado responsabilidades que não são apenas de desenvolvimento de conteúdos, mas de uso social que os alunos devem fazer desses conteúdos na vida prática. Isto posto, exige-se dos profissionais docentes conhecimentos além de currículos específicos de disciplinas, mas que tenham habilidades de contribuir para que os estudantes consigam desenvolver-se em suas vidas diárias.

Nesse âmbito, o presente estudo, na perspectiva da narrativa autobiográfica, tem como objetivo apresentar e analisar aspectos relativos à ação social responsável a partir de práticas de letramento científico e matemático desenvolvidas com uma turma de quinto ano do Ensino Fundamental na cidade de Belém-Pa. Assim, a questão de pesquisa se expressa nos seguintes termos: de que forma práticas de letramento científico e matemático contribuem para tomadas de decisão conscientes por alunos dos anos iniciais na perspectiva da ação social responsável?

O letramento científico, de acordo com Santos e Mortimer (2001), tem como objetivo levar os estudantes à compreensão da forma como Ciência e Tecnologia se influenciam mutuamente, além de torná-los capazes de fazer uso do conhecimento científico e tecnológico para resolverem problemas no dia a dia e a tomarem decisões com responsabilidade social. Rocha, Lorenzetti e Kalinke (2019) afirmam que, cabe à escola, sendo uma instituição influenciada pela ciência e pela tecnologia, integrar tais conhecimentos à sala de aula com o objetivo de serem incorporados pelos alunos.

O letramento matemático, de acordo com a OCDE/PISA (2004), Organização para Cooperação e Desenvolvimento Econômico/Programa Internacional de Avaliação de Estudantes, está relacionado com a capacidade de um indivíduo identificar e compreender o papel que a Matemática desempenha no mundo real, além de fazer julgamentos bem fundamentados e de usar e se envolver na resolução matemática das necessidades de sua vida, enquanto cidadão consciente, construtivo e reflexivo.

Diante desse cenário de conceituações, resolvi trabalhar com os alunos na perspectiva da tomada de decisão responsável como fator importante para o exercício da cidadania. Dessa forma, a atividade proposta requeria posicionamentos críticos dos estudantes no sentido de aparecerem como agentes sociais responsáveis que sabem fazer uso de conhecimentos científicos e matemáticos em situações que Ihes sejam exigidos tal posicionamento. $\mathrm{Na}$ condição de docente que pesquisa e reflete sobre a própria prática, as atividades 
desenvolvidas deram-me a possibilidade de compreender a ação social responsável como fator imprescindível a ser ampliado nas interações de sala de aula com alunos em fase inicial de estudos.

Nesse contexto, a autobiografia que apresento é relativa às narrativas dos alunos pesquisados quanto às suas tomadas de decisão para a ação social responsável, o que não inviabiliza que, ao desenvolver o presente diálogo, apareçam autorreflexões de minha parte enquanto pesquisador, mas também na condição de docente, pois as narrativas possibilitam "[...] refletir sobre a própria prática quanto a expectativas e sentimentos ante a realidade escolar" (SELINGARDI; MENEZES, 2017, p. 275).

\section{METODOLOGIA}

Esta pesquisa assume caráter qualitativo na perspectiva da narrativa autobiográfica. A pesquisa qualitativa, de acordo com Silva e Trintin (2017) preocupa-se em interpretar fenômenos não quantificáveis, além de permitir a atribuição de significados sobre as ações dos sujeitos. A narrativa autobiográfica se constitui em uma forma única de lembrar e contar a própria história de vida que está em interação com o eu, o outro e o mundo (SILVA; MAIA, 2019). Ainda segundo estes autores, a narrativa autobiográfica configura-se como uma possibilidade de reflexão, autoconhecimento e socialização da experiência vivida. Com essa perspectiva apresento os dados da pesquisa realizada com base nas práticas de letramento científico e matemático possibilitadas por meio da interação entre a sociedade que nos rodeia, os alunos e por mim mesmo no exercício da docência e da atividade de pesquisa.

Além das seções introdutória e metodológica, desenvolvo este artigo em mais duas seções: na próxima apresento uma breve revisão da literatura sobre a narrativa autobiográfica como metodologia de pesquisa importante para quem pesquisa a própria prática, e sobre o letramento científico e o letramento matemático como parâmetros para a ação social responsável; na última seção discorro sobre a atividade interdisciplinar desenvolvida em sala de aula e analiso as tomadas de decisão dos alunos.

Para a produção do material empírico utilizo: i) atividade interdisciplinar, adotada por mim, para criar um ambiente favorável às práticas de ação social responsável sob a ótica do letramento científico e matemático. Tal atividade esteve circunscrita à temática merenda escolar, motivada pelos próprios estudantes no âmbito da escola e bastante questionada dadas algumas situações que esclarecerei na seção de análise; ii) rodas de conversa realizadas antes e após cada atividade desenvolvida; iii) atividades escritas dos alunos; iv) e meus registros em diário de campo.

De forma complementar à produção dos dados e relativamente às atividades escritas dos alunos, dois outros momentos foram registrados e também serão apresentados: atividade de produção de dados sobre a preferência dos estudantes quanto aos tipos de alimentos servidos na escola; e escrita coletiva de uma carta dirigida à Secretária de Educação do Estado com os dados encontrados na pesquisa. Essas atividades contribuíram, sobremaneira, ao processo de ensino e aprendizagem do letramento científico e matemático. 
Como forma de garantir a ética e o rigor científicos, identifico os discentes, quando necessário, usando letras maiúsculas do alfabeto. Além disso, apresento suas falas em negrito. Cinco são as narrativas sobre as quais lanço um olhar analítico. Ressalto que, por conta da extensão dos discursos, apresento trechos breves no intuito de deixá-los coerentes à análise desenvolvida.

\section{NARRATIVA AUTOBIOGRÁFICA, LETRAMENTO CIENTÍFICO E LETRAMENTO MATEMÁTICO}

Atualmente, e a partir da onda política instalada em nosso país, me parece salutar, a nós, professores dos anos iniciais, o desenvolvimento de atividades cada vez mais vinculadas ao dia a dia das crianças e ao que vivenciam em suas práticas diárias. Nesse sentido, nosso propósito deve ser o de contribuir para que se tornem cidadãos críticos, autônomos e agentes de renovação (CACHAPUZ et al., 2005).

Para tratar de práticas de letramento científico e matemático nos anos iniciais, elegi a narrativa autobiográfica com o propósito de compartilhar a experiência vivida com alunos do quinto ano na perspectiva da ação social responsável. A narrativa autobiográfica configura-se como uma metodologia de pesquisa significativa para quem pretende coletivizar aspectos da própria prática profissional sob a forma de pesquisa. Assim, de acordo com Silva e Maia (2019):

[...] as narrativas autobiográficas, quer dizer, os relatos orais ou escritos de professores acerca de suas experiências formativas vivenciadas ao longo da vida, no contexto da trajetória de escolarização e/ou da prática profissional, configuram-se como técnica e procedimento de produção de dados, subsidiando o estudo da formação e do trabalho docente em seus mais diversos aspectos (SILVA; MAIA, 2019, p. 02).

Assumindo a narrativa autobiográfica como expressão de relatos orais ou escritos de professores em relação à prática profissional, busco, no contexto da sala de aula pesquisada, evidenciar aspectos relevantes que têm contribuído para tomadas de decisão conscientes. Tais aspectos configuram-se como material empírico importante para as atividades analisadas que seguirão mais adiante.

Para Marques e Satriano (2017) a narrativa encontra-se evidente não somente em construções orais e escritas, mas em todos os discursos da experiência humana, como na música, nas lendas, nas pinturas ou em conversações. Dessa forma, ao narrar, o ser humano busca interpretar a realidade atribuindo-lhe sentido.

No exercício da profissão docente fazer uso da narrativa autobiográfica para relatar aspectos da própria prática significa, a meu ver, valorizar o trabalho docente a partir de uma epistemologia da prática vivida e experienciada. Assim, tenho a oportunidade de revelar, singularmente, aspectos profissionais na relação estabelecida entre os alunos, o mundo e eu. Logo, a narrativa autobiográfica me permite considerar o ambiente da sala de aula como espaço de pesquisa, formação e autoformação.

Na narrativa autobiográfica, seja ela oral, escrita ou sob a forma de outra produção, o pesquisador, que também é narrador, produz um texto no qual constam suas impressões que estão impregnadas de suas vivências e associações acerca daquilo que produz (MARQUES; SATRIANO, 2017). Em meu caso, minhas 
produções enquanto pesquisador narrador, são relativas à pesquisa desenvolvida com os alunos. Destaco que esse movimento de narrar e investigar a própria prática educativa é um processo complexo e exige desprender-me daquilo que é definido e moldurado sobre o ser (SOARES; SALES; FRAIHA-MARTINS, 2018).

Narrativas autobiográficas comumente permitem, a quem escreve, autorreflexões a partir do movimento de lembrar o que está na memória a partir de uma ação investigada, o que me leva a analisar as práticas desenvolvidas sob um olhar investigativo (SOARES; SALES; FRAIHA-MARTINS, 2018). Nesse sentido, encontro, nas autorreflexões, sentidos formativos que contribuem para a melhoria das práticas docentes quanto à temática abordada neste texto.

Considerações importantes a respeito das narrativas autobiográficas são elucidadas por Nascimento e Hetkowski (2007):

\footnotetext{
Nas pesquisas na área da educação adota-se a história de vida, mais especificamente o método autobiográfico e as narrativas de formação, como movimento de investigação-formação, seja na formação inicial ou continuada de professores/professoras. [...] Através da abordagem biográfica o sujeito produz um conhecimento sobre si, sobre os outros e o cotidiano, revelandose através da subjetividade, da singularidade, das experiências e dos saberes (NASCIMENTO; HETKOWSKI, 2007, p. 67-69).
}

Considerada narrativa de formação, seja inicial ou continuada, e ainda acrescento, no exercício da profissão, o método autobiográfico possibilita que professores produzam conhecimentos sobre suas práticas, sobre a forma como aprendem os alunos e sobre o cotidiano do qual somos parte integrante e que denota nossas experiências e saberes. Dessa forma, as narrativas autobiográficas estão intimamente relacionadas às práticas sociais dos seres humanos.

Na perspectiva das práticas sociais com as quais nos envolvemos diariamente, outro conceito que trago nesse artigo é o de letramento científico, o qual é o principal objetivo de currículos CTS (ciência, tecnologia, sociedade) possibilitando aos estudantes atuarem efetivamente como cidadãos tomando decisões e agindo com responsabilidade social (SANTOS; MORTIMER, 2001).

Na direção da tomada de decisão responsável, "[...] o letramento científico enfoca as práticas sociais de uso do conhecimento científico, tanto em termos práticos quanto cívicos, no exercício da cidadania, na vida cotidiana" (CUNHA, 2018). Nos anos iniciais do Ensino Fundamental espera-se que os alunos sejam letrados cientificamente a partir dos conteúdos científicos ou partindo de fatos do cotidiano, os quais devem estar articulados no sentido de convergirem para reflexões sobre os usos sociais que eles podem fazer, inclusive sabendo se expressar através de vocabulário científico.

De acordo com Santos (2007), o letramento científico, como um dos domínios da educação científica, é entendido como uma prática de uso social que os indivíduos podem fazer da relação ciência-tecnologia-sociedade em suas vidas diárias, possibilitando-Ihes tomar decisões pessoais e coletivas para um bem comum. Nesse sentido, segundo as motivações do autor, uma pessoa letrada cientificamente saberia tomar posicionamento em uma assembleia que buscasse providências junto a órgãos públicos sobre problemas sociais que afetam a comunidade no que diz respeito a assuntos relativos à ciência e à tecnologia. 
Ressalto que, na área do ensino de ciências, comumente encontramos na literatura autores que usam a expressão letramento científico e autores que empregam alfabetização científica, mas que, ambas, por serem domínios da educação científica encontram-se relacionadas. Nesse contexto, Sasseron e Machado (2017) supõem que, em algum momento, já ouvimos a expressão Alfabetização Científica ou suas variantes, como Letramento Científico e Enculturação Científica. Os autores adotam a Alfabetização Científica para se referir ao ensino de Ciências cujo objetivo é formar o indivíduo para que consiga resolver problemas recorrentes em seu dia a dia tendo em vista os saberes possibilitados pelas Ciências. Ainda segundo os autores, o aluno cientificamente alfabetizado deve estar capacitado para tomadas de decisão que estejam fundamentadas em situações de seu cotidiano e que vão influenciar, de uma forma ou de outra, em sua vida e em seu futuro.

Discutindo possíveis interações entre alfabetização científica, criança e educação não formal, Marques e Marandino (2018) apresentam uma visão, em minha opinião, esclarecedora sobre o que entendem por alfabetização científica:

\begin{abstract}
Entendemos a AC como processo que ocorre dentro e fora da escola e que implica: i) a promoção de diálogos e aproximações entre a cultura experiencial dos indivíduos e a cultura científica; ii) a aproximação de saberes relacionados a termos e conceitos científicos, à natureza da ciência, às relações entre ciência, tecnologia e sociedade; iii) à promoção de condições necessárias à realização de leituras críticas da realidade, à participação no debate público, à tomada de decisão responsável, à intervenção social em uma perspectiva emancipadora e de inclusão social; também a construção do que Freire chama de consciência epistemológica, potencializando a participação social (MARQUES; MARANDINO, 2018, p. 07).
\end{abstract}

É interessante observar que Marques e Marandino (2018) parecem reunir, em um único discurso, todas as características que devem ter os cidadãos para serem considerados cientificamente letrados. Portanto, a alfabetização científica, ou o letramento científico, como estou chamando nesse trabalho, se traduz em um processo que ocorre não apenas no contexto escolar, mas fora dele também, e que envolve, além de saberes relativos a termos e conceitos científicos, a tomada de decisão responsável que potencializa a participação social dos indivíduos.

Nessa mesma linha de pensamento, do agir em sociedade de forma responsável, outro conceito trabalhado com os alunos foi o de letramento matemático. Com perspectiva semelhante à do letramento científico, o letramento matemático refere-se à:

[...] capacidade de um indivíduo identificar e compreender o papel que a Matemática desempenha no mundo real, de fazer julgamentos bem fundamentados e de usar e se envolver na resolução matemática das necessidades de sua vida enquanto cidadão consciente, construtivo e reflexivo (OCDE/PISA, 2004, p. 24).

É preciso entender que a definição apresentada pela OCDE/PISA (2004) traz, em seu bojo, um papel social desempenhado pela Matemática no mundo real do qual todos fazemos parte. Assim, fica claro que a Matemática está presente na vida do cidadão que deve utilizá-la de modo a resolver problemas de seu cotidiano. Ser construtivo e reflexivo, nesse contexto, significa saber se desenvolver 
matematicamente em direção de soluções plausíveis diante das necessidades da vida real.

De acordo com Aguiar e Ortigão (2012, p. 08) o letramento matemático “[...] remete à capacidade de o aluno aplicar seus conhecimentos, analisar, raciocinar $\mathrm{e}$ se comunicar com eficiência, à medida que expõe, resolve e interpreta problemas em diversas situações". Ainda segundo os autores, o termo letramento reflete à amplitude de conhecimentos, habilidades e competências que são avaliados nos alunos, além de um processo de aprendizagem que ocorre ao longo da vida.

Entendo que, aos professores, particularmente os que trabalham com crianças, deve ser fundamental possibilitarem a vivência, por parte dos alunos, de situações de contexto sociocultural em que a Matemática seja compreendida como um conhecimento que contribui para a resolução de problemas relacionados às nossas práticas sociais diárias enquanto cidadãos.

Agir criticamente na sociedade, de acordo com Galvão e Nacarato (2013), é algo relacionado ao letramento matemático que, segundo suas motivações, significa:

[...] saber aplicar as práticas de leitura, escrita matemática e habilidades matemáticas para resolver problemas não somente escolares, mas de práticas sociais como: saber ler e interpretar gráficos e tabelas, fazer estimativas, interpretar contas de luz, telefone, água e demais ações relacionadas aos diferentes usos sociais (GALVÃO; NACARATO, 2013, p. 84).

É importante perceber que, para usar a Matemática em práticas sociais cotidianas, Galvão e Nacarato (2013) não descartam as práticas de leitura e escrita Matemática na escola. Entendo que cabe à escola e aos professores apresentar, de forma institucionalizada, os conceitos matemáticos para as crianças, não perdendo de vista a vivência que elas trazem do cotidiano para a sala de aula. Em outro momento do trabalho desenvolvido pelas autoras, elas argumentam que a escolha do termo letramento matemático "[...] nos dá uma ideia profícua, mais ampla, sobre o uso da matemática nas práticas sociais [...]" (GALVÃO; NACARATO, 2013, p. 84).

Fazer uso da Matemática com responsabilidade social permite aos alunos e aos seres humanos, de forma geral, que detenham diversas habilidades, entre elas: a de saber ler e interpretar gráficos e tabelas, instrumentos esses muito difundidos atualmente, sobretudo em pesquisas de opinião realizadas por órgãos competentes; interpretar contas de luz, água, telefone, que são serviços presentes na vida do cidadão e sobre os quais incidem impostos; saber organizar a economia pessoal; compreender dados sobre peso, altura, medidas e suas implicações para a saúde.

De modo a contemplar tudo o que se disse até aqui sobre letramento matemático, a Base Nacional Comum Curricular (BNCC) afirma: letramento matemático, definido como as competências e habilidades de raciocinar, representar, comunicar e argumentar matematicamente, de modo a favorecer o estabelecimento de conjecturas, a formulação e a resolução de problemas em uma variedade de contextos, utilizando conceitos, procedimentos, fatos e ferramentas matemáticas (BRASIL, 2017, p. 222). 
Com esse ponto de vista da BNCC, entendo que o letramento matemático propicia aos estudantes reconhecerem que, para atuarem e compreenderem o mundo, os conhecimentos matemáticos são fundamentais, pois, além de estimularem a investigação, contribuem para o desenvolvimento do raciocínio lógico e crítico. Dessa forma, é possibilitada a tomada de decisão responsável frente aos desafios impostos pela sociedade.

\section{AÇÃO SOCIAL RESPONSÁVEL: LETRAMENTO CIENTÍFICO E MATEMÁTICO EM UMA PRÁTICA INTERDISCIPLINAR}

Nesta seção analiso uma prática pedagógica interdisciplinar que foi desenvolvida, como já dito, com alunos do quinto ano do Ensino Fundamental. $\mathrm{O}$ objetivo é apresentar, por intermédio da ação social responsável, as tomadas de decisão dos estudantes frente a uma situação do cotidiano apresentada por eles mesmos. O intuito foi o de fazê-los refletir, analisar, julgar e avaliar que alternativas poderiam ser eleitas para fundamentar suas motivações.

É importante destacar que, embora esteja tratando de letramento científico e matemático, as práticas pedagógicas realizadas com os estudantes possuem caráter interdisciplinar. Para Thiesen (2008, p. 547) a interdisciplinaridade "[...] será sempre uma reação alternativa à abordagem disciplinar normalizadora (seja no ensino ou na pesquisa) dos diversos objetos de estudos". O autor acredita que, tratar de interdisciplinaridade, significa superar a fragmentação do conhecimento científico. Portanto, entendo que as atividades desenvolvidas em sala de aula deveriam ser sempre interdisciplinares com o objetivo de possibilitar aos alunos uma visão mais ampla do conhecimento.

No primeiro momento, em uma roda de conversa inicial, dialogamos sobre as percepções dos estudantes relativas à merenda que é distribuída na escola. Dessa forma, busquei garantir o direito à fala coletiva da classe. Entendo que, propiciar eventos de fala, especialmente aos alunos dos anos iniciais, é fundamental e desenvolve o senso crítico. Nesse sentido, a linguagem oral tem sido considerada como um dos aspectos fundamentais da vida, pois nos permite a socialização, a construção de conhecimentos, a organização de nossos pensamentos e experiências, além de ser por meio dela que ingressamos no mundo; portanto, a oralidade permite ampliarmos nossas possibilidades de inserção e de participação em práticas sociais (CHAER; GUIMARÃES, 2012).

O aluno A fez o seguinte comentário: Tio, os alimentos são importantes porque ajudam a gente a ter boa saúde e também a estudar melhor. Partindo da premissa da importância da alimentação para o bom funcionamento do organismo, chamo a atenção para a relação estabelecida pelo estudante entre alimentação e estudos, pois, em sua concepção, quem se alimenta bem possui desempenho satisfatório em atividades que envolvam o intelecto. Mattos, Rocha e Rodrigues (2018) garantem que a saúde mental, por abranger cuidados com os indivíduos de forma ampliada, está relacionada com boas práticas de alimentação.

A aluna B, em minha visão, completa o pensamento do aluno anterior ao dizer: Os alimentos são importantes para a saúde. Por isso que a escola tem que dar bons alimentos e eles têm que ser gostosos. Evidentemente que, ao se referir ao fato de que a escola "deve dar bons alimentos", a aluna faz alusão ao compromisso 
que, neste caso, o governo estadual deve assumir ao ter de garantir cardápio nutricional adequado às crianças. Loureiro (2004) afirma que práticas de alimentação saudável devem ser responsabilidade social, portanto, além de função do poder público, também é de pais, professores e da sociedade civil.

Um terceiro posicionamento, da aluna C, chama a atenção pela qualidade da visão crítica apresentada. Ela assim se expressa: Eu acho que a alimentação da escola deve melhorar porque a gente não consegue aprender direito com fome. $E$ também nossos pais pagam os impostos. Nitidamente a aluna se mostra conhecedora dos seus direitos como estudante e como cidadã. Ela entende que, se seus pais pagam impostos, estes devem voltar a eles como benefícios sociais. Este tipo de posicionamento faz parte de quem pode ser considerada como alguém letrada cientificamente, uma vez que demonstra conhecimento necessário para se desenvolver na vida diária (SANTOS, 2007).

Desse momento inicial, surgiram observações relativas aos tipos de alimentos consumidos pelos estudantes no recreio da escola. De posse dessa informação, resolvi, na qualidade de pesquisador, propor aos alunos a realização de uma pesquisa com os demais estudantes da instituição sobre suas preferências em relação aos tipos de alimentos que são servidos na merenda escolar. Dessa forma, trabalhamos aspectos característicos do letramento matemático em práticas sociais (GALVÃO; NACARATO, 2013).

Com meu auxílio, os alunos elaboraram um questionário de pesquisa com informações relevantes para saber, dentre os alimentos citados na roda de conversa, qual o mais apreciado pelos demais estudantes. Os mais citados foram: açaí, frutas, suco, café, bolacha e comida. A tabela 1 mostra, em ordem, a preferência dos demais discentes após o levantamento dos dados realizado.

Tabela 1 - Preferência dos alunos de acordo com o tipo de alimento

\begin{tabular}{|c|c|c|}
\hline Ordem & Alimentos & Votos recebidos \\
\hline 10 & Açaí & 29 \\
\hline 2 & Frutas & 10 \\
\hline 3 & Comida & 9 \\
\hline 4 & Bolacha & 5 \\
\hline 5 & Suco & 1 \\
\hline 60 & Café & 29 \\
\hline
\end{tabular}

Fonte: Autoria própria (2019).

Somando-se à tabela 1, e por já haverem trabalhado com gráficos em sala de aula, propus aos alunos a elaboração desse instrumento para melhor visualizarem os dados da pesquisa. Entretanto, tal instrumento será apresentado posteriormente, junto à carta que foi escrita e destinada à Secretária de Educação do Estado. Considero esse movimento como tomada de decisão para a ação social e que, de acordo com Santos e Mortimer (2001, p. 101), "A tomada de decisão em uma sociedade democrática pressupõe o debate público e a busca de uma solução que atenda aos interesses da maior parte da coletividade".

Além do levantamento sobre as preferências alimentares dos estudantes da instituição, outra questão que se pôs aos entrevistados foi: o que você acha dos 
alimentos que são servidos na merenda da escola? Aqui destaco, uma vez mais, a questão social que deu origem à presente produção textual: o questionamento feito pelos discentes relativo à qualidade da alimentação que lhes é servida. Novamente em roda de conversa, pedi aos alunos que socializassem, após terem exercitado a escrita, a que conclusões poderiam chegar uma vez com os dados da pesquisa em mãos.

Nesse momento da discussão sinalizo a perspectiva do letramento científico com base nas considerações de Fumeiro et al. (2019, p. 156) para os quais a alfabetização científica e tecnológica "[...] proporciona ao ser humano fazer uma leitura atual do meio em que está inserido, para que, ao compreendê-lo, proponha mudanças".

Com essa perspectiva debatemos os resultados encontrados e surgiram falas como da aluna D: Os alunos gostam mais de açaí, mas a merenda precisa melhorar mais porque às vezes ele tá azedo. $O$ fato do açaí ter recebido a maior quantidade de votos não foi por acaso. Em Belém, trata-se de um alimento típico, parte integrante da culinária paraense, servindo, muitas vezes, como principal refeição de muitas famílias. Questões como essa foram conversadas com as crianças fazendo-as refletir sobre a origem do alimento ligada à lenda do açaí. Aproveitei e destaquei aspectos relativos à história e à geografia da região relacionando-a à produção do alimento e ao seu nome científico.

Chamo a atenção para o questionamento feito pela aluna $D$ relativo ao fato do açaí estar azedo em algumas situações em que é servido. Exatamente por queixas como essa, constantemente repetidas entre as crianças, que a temática proposta na presente investigação ganhou interesse de minha parte. Contudo, muito mais do que relatar a situação à direção da escola, decidi envolver a comunidade estudantil para que, juntos, pudéssemos encontrar possíveis soluções ao caso inserindo-os no contexto da ação social responsável.

As observações das crianças se estendem também a outros alimentos como os citados pelo aluno A: Outro dia a banana e a tangerina estavam estragadas. $\mathrm{E}$ ainda pelo aluno E: Deve ter comida saudável. O modo de preparar a comida deve mudar, deve ter mais higiene. Já a algum tempo os alunos da escola vêm apresentando queixas sobre a forma como a merenda lhes é servida ou preparada. Ao que parece eles têm percebido falta de higienização adequada e os devidos cuidados no armazenamento dos alimentos de modo que permaneçam saudáveis.

Outro comentário relacionado com os dados obtidos e com a pergunta sobre o que os alunos acham da merenda servida na escola foi o da aluna C: Eu entendi que a merenda não tá muito boa, tem que melhorar. Eles (os alunos pesquisados) não gostam muito de café e de bolacha, precisamos ter mais frutas. Pelas falas na roda de conversa, entendo que as crianças gostam da merenda escolar, porém acreditam que a forma como é preparada pode melhorar. Além disso, quando se reportam à questão de ter mais frutas, estão se referindo à variedade delas, pois, normalmente, só recebem banana e tangerina.

Como dito anteriormente, além das atividades realizadas no domínio da Matemática, de Ciências, História e Geografia, propus aos alunos, após os debates feitos, a escrita de uma carta à Secretária de Educação com o objetivo de exporIhe os dados encontrados na pesquisa e o posicionamento dos estudantes frente a situação. Desta forma, garanti o letramento científico das crianças com base na 
proposição de Santos e Mortimer (2001) quando escrevem sobre tomada de decisão:

\begin{abstract}
São os temas vinculados à vida dos alunos que possibilitam a prática de habilidades básicas para a tomada de decisão, como a realização de pesquisas em bibliotecas, o levantamento de dados e informações confiáveis em agências governamentais ou privadas, a aplicação de questionários e entrevistas para coletar dados de sua comunidade (SANTOS; MORTIMER, 2001, p. 104).
\end{abstract}

Pensando na perspectiva de Santos e Mortimer (2001), os alunos trabalharam exatamente com um tema pertinente à vida deles, o que lhes possibilitou, por intermédio dos dados da pesquisa que realizaram, tomadas de decisão conscientes quanto as providências que deveriam tomar para tentar resolver o problema da comunidade da qual fazem parte, a discente. Nesse sentido, a seguinte carta foi escrita coletivamente:

Quadro 1 - Carta à Secretaria de Educação

\title{
Resultado de pesquisa realizada quanto à preferência alimentar dos alunos
} Senhora Secretária de Educação,

Somos alunos do 50 ano da Escola Estadual de Ensino Fundamental Fulano de Tal, localizada no bairro do Guamá. Com as devidas orientações, realizamos uma pesquisa sobre os tipos e as condições dos alimentos que consumimos na merenda escolar e tivemos os resultados que aparecem no gráfico abaixo:

Gráfico 1 - Preferência dos alunos em relação à merenda escolar

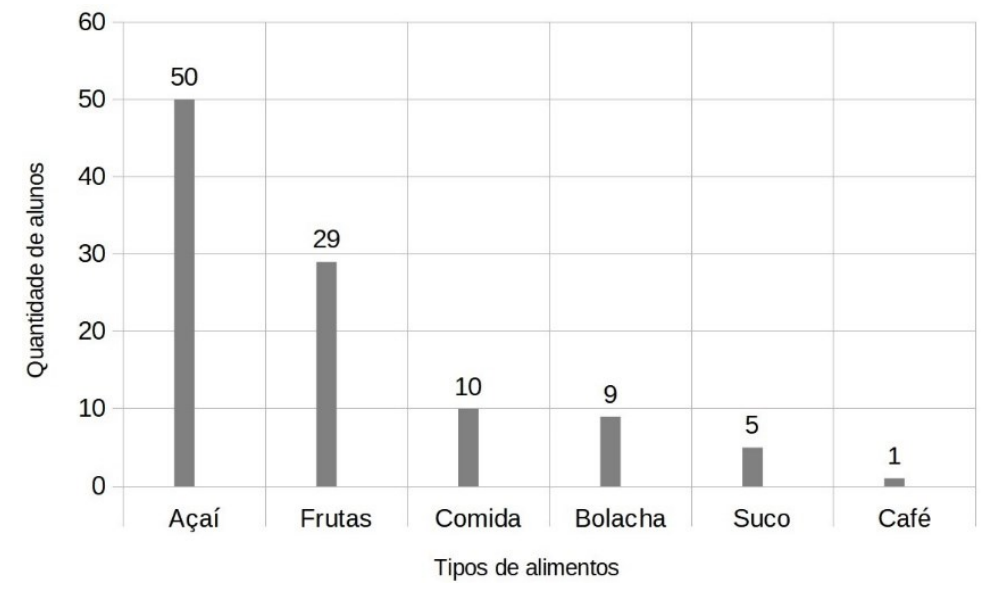

Fonte: Autoria própria (2019).

Como a senhora pode ver, o lanche preferido dos alunos é o açaí, produto que faz parte do nosso dia a dia. O segundo alimentado mais votado foram as frutas, porém gostaríamos que a qualidade desses alimentos melhorasse, pois muitas vezes o açaí chega azedo e as frutas meio estragadas.

Pelas coisas que estamos citando, gostaríamos de pedir que a senhora pudesse melhorar a nossa merenda, pois, como é de seu conhecimento, precisamos estar bem alimentados para ter uma boa aprendizagem.

Ficaremos aguardando uma resposta da senhora e, desde já, agradecemos a sua atenção. Atenciosamente, os alunos da turma do 5o ano. 
É importante destacar que a carta, enquanto atividade voltada à área de linguagens, mas na perspectiva do letramento científico e matemático, foi escrita com a participação de todos os alunos da turma. Em minha percepção, a atividade de pesquisa com os demais estudantes da escola pareceu motivar os pequenos pesquisadores a querer expor suas ideias de tal forma que todos tiveram a oportunidade de assinar o documento individualmente.

Relativamente ao letramento científico, o posicionamento crítico dos alunos mediante a situação vivenciada, permite considerá-los, senão cientificamente letrados em sentido amplo (MARQUES; MARANDINO, 2018), mas em processo de quem sabe tomar decisões responsáveis levando em consideração que elas podem ser impactantes para toda uma coletividade. Nesse sentido, concordo com Rubba (1991), apud Santos e Mortimer (2001), quando afirmam que o objetivo da educação para a ação social responsável é:

[...] preparar o cidadão para tomar decisões com consciência do seu papel na sociedade: o de indivíduo capaz de provocar mudanças sociais na busca de melhor qualidade de vida para toda a população. Isso incluiria conscientizar o cidadão quanto aos seus deveres na sociedade, sobretudo no que se refere ao compromisso de cooperação e corresponsabilidade social, na busca conjunta de solução para os problemas existentes (RUBBA, 1991, apud SANTOS; MORTIMER, 2001, p. 102).

Pensando sob a ótica da ação social responsável, conforme assinalado pelos autores, percebo que, mesmo com poucas palavras escritas na carta, os alunos da turma do quinto ano avançaram no entendimento da tomada de decisão coletiva para o bem comum e da percepção do conhecimento matemático para resolver problemas do cotidiano.

É importante mencionar que a resposta da Secretária de Educação até o presente momento ainda não foi enviada aos alunos. Contudo, pensando que isso poderia acontecer, solicitei à diretora da instituição que participasse de uma das rodas de conversa para que os próprios discentes entregassem o documento, que deveria ser ratificado por ela, e para apresentar-lhe os argumentos e a pesquisa Matemática feita. Após ouvi-los, a diretora comprometeu-se em conversar com a senhora que prepara a merenda no sentido de orientá-la melhor quanto ao modo de preparo dos alimentos servidos, além de parabenizá-los pelo trabalho desenvolvido.

Ainda no tocante às práticas de letramento matemático, os alunos buscaram, de acordo com a BNCC (BRASIL, 2017), raciocinar, representar, comunicar e argumentar matematicamente sobre uma questão social posta e de interesse de sua comunidade. Para tanto, a escrita da carta com argumentos matemáticos, revela a tomada de consciência dos estudantes para um problema social vivenciado por eles mesmos. Logo, os discentes foram capazes de expressar suas ideias matemáticas de modo a conseguir resultados favoráveis para a comunidade de alunos.

Após a escrita da carta, pedi aos alunos que comentassem, espontaneamente, o que acharam da forma de estudar a que foram submetidos. Destaco duas falas que sinalizam a compreensão dos discentes a respeito do letramento científico e matemático na perspectiva da ação social responsável. O aluno $E$ assim se expressou: Foi mais fácil e divertido. A gente pode estudar matemática pra tentar 
resolver a forma que a merenda é servida na escola. $\mathrm{O}$ argumento do aluno diz respeito à capacidade que ele e os colegas tiveram de saber se posicionar, enquanto cidadãos, utilizando-se do papel que a Matemática tem em práticas sociais e do sentido que atribuímos aos códigos numéricos na vida cotidiana (SOUZA; MOLL; ANDRADE, 2019).

A aluna B destaca: Conversando dessa forma com os colegas a gente consegue falar sem medo... até pra resolver a situação da merenda a gente fez tudo junto. A "forma" a que a aluna se refere está relacionada com a configuração da sala de aula nos momentos das rodas de conversa. Quando ela afirma ter feito tudo junto com os colegas, pode-se perceber a tomada de decisão responsável e coletiva para o bem comum, aspecto esse possibilitado pelo letramento científico de acordo com Santos (2007) e Marques e Marandino (2018).

De acordo com os relatos e com as atividades desenvolvidas fica evidente que, dotar um indivíduo de conhecimentos necessários para tomadas de decisão responsáveis, seja em ciência e tecnologia, seja em matemática, é tarefa que demanda tempo, disposição e compromisso com a formação cidadã na perspectiva da ação social responsável. Por isso a necessidade de professores, na condição de sujeitos que colaboram para a construção do conhecimento, estarem em constante formação.

\section{CONSIDERAÇÕES FINAIS}

Práticas de letramento científico e matemático são atividades ainda pouco desenvolvidas com alunos dos anos iniciais do Ensino Fundamental. A tradição livresca tende a apresentar a Ciência e a Matemática como disciplinas curriculares a serem memorizadas e, portanto, sem nenhuma significação cultural e prática para as crianças. Em nosso país ainda precisamos superar paradigmas que entendem a educação dos primeiros anos de escolarização como "fácil" de ser ensinada. Talvez faltem-nos processos formativos mais comprometidos, de fato, com o exercício consciente da cidadania.

Com a atividade desenvolvida percebe-se que as crianças dos anos iniciais são muito mais do que indivíduos que vão à escola para aprender a ler, escrever ou fazer cálculos. São pequenos pesquisadores e cientistas! Têm consciência de que, para o pleno exercício da cidadania, podem e devem ser escutados por meio das decisões coletivas para o bem da comunidade, conforme se percebe na narrativa da aluna C: Eu entendi que a união faz a força. Porque se a gente estudar direito vamos aprender muitas coisas que são importantes para nossa vida, até mesmo vamos saber como usar nossos direitos. Mas não podemos esquecer que também temos deveres.

Além de fomentar a participação social, as práticas de letramento científico e matemático contribuíram para o desenvolvimento de uma consciência crítica que possibilitou às crianças reverem posicionamentos e atitudes, transformando-se epistemologicamente ao longo do processo formativo vivenciado. Nesse sentido, posso afirmar que as ações desenvolvidas com os alunos favoreceram um olhar crítico em busca da justiça social e de valores relativos à democracia.

No contexto da pesquisa desenvolvida, posso afirmar que o desenvolvimento da responsabilidade social pelos alunos se deu a partir das atitudes questionadoras 
em relação à merenda escolar, o que Ihes permitiu agir na transformação social do que vivenciam apesar de ainda não terem tido resposta da Secretária de Educação, mas respaldados pelo compromisso assumido pela diretora da instituição. A esse respeito, destaco as observações do aluno E: Achei muito legal porque foi a primeira vez que a diretora veio falar com a gente para a gente dizer para ela que a merenda não estava boa. A gente até mostrou a pesquisa que fizemos usando a Matemática.

As atividades de discussão no grupo, além de fundamentais para a aquisição de informações significativas para a formação dos alunos enquanto cidadãos, contribuíram para a autoconfiança e para o processo de refinamento da argumentação, sobretudo quanto à redação do documento encaminhado e discutido com a diretora da escola. De acordo com Santos e Mortimer (2001), existem estudos que comprovam a importância da argumentação em processos de tomada de decisão.

Pensando na formação para o exercício da cidadania e da efetiva participação social, creio que "[...] a escola deve propiciar situações de ensino-aprendizagem que vise a participação dos sujeitos que a compõem, mediados pelo diálogo, postura reflexiva, autonomia e engajamento social." (FUMEIRO et al, 2019, p. 159). Por isso a importância em contextualizar os conhecimentos universais às problemáticas sociais, pois contribuem para a formação de sujeitos críticos e reflexivos que lutam para a transformação societária.

Entendo, por fim, que, além de apresentar conceitos científicos e matemáticos na escola, devemos preparar os alunos para a participação e engajamento em decisões sociais na perspectiva de uma educação relativa à ação social responsável na busca de construções coletivas para o bem comum. 


\title{
Responsible social action: scientific and mathematical literacy practices in the initial years of elementary education
}

\begin{abstract}
Acting with social responsibility is one of the goals desired for students in the early years of elementary school. Encouraging, through the teaching of science and mathematics, conscious making decision aiming at the exercise of citizenship, allows children to act expressively in the various social contexts of which they are part. In this context, this qualitative study, with the perspective of autobiographical narrative, has the goal of to present and to analyze aspects related to responsible social action based on scientific and mathematical literacy practices developed with a fifth grade class in the city of Belém-PA, in Brazil. For the production of empirical material, I use an interdisciplinary activity, adopted by me to create a favorable environment for responsible social action practices in the perspective of scientific and mathematical literacy, as well as discussion about the proposed themes, students' written activities and my field journal entries. The results point out that, by providing scientific and mathematical literacy activities in the classroom, students tend to position themselves with social responsibility in different life contexts, which encourages them to make conscious decisions and to exercise citizenship effectively.
\end{abstract}

KEYWORDS: Scientific and mathematical literacy. Autobiographical narrative. Social responsibility. 


\section{REFERÊNCIAS}

AGUIAR, G. S.; ORTIGÃO, M. I. R. Letramento em matemática: um estudo a partir dos dados do PISA 2003. Bolema, Rio Claro (SP), v. 26, n. 42 A, p. 1-21, abr., 2012.

BRASIL. Ministério da Educação. Base Nacional Comum Curricular. Proposta preliminar. Segunda versão revista. Brasília: MEC, 2016. Disponível em: http://basenacionalcomum.mec.gov.br/documentos/bncc-2versao.revista.pdf. Acesso em: 23 mar. 2017.

CACHAPUZ, A.; GIL-PÉREZ, D.; CARVALHO, A. M. P. de; PRAIA, J.; VILCHES, A. A necessária renovação do ensino das ciências. São Paulo: Cortez, 2005.

CHAER, M. R.; GUIMARÃES, E. da G. A. A importância da oralidade: educação infantil e séries iniciais do Ensino Fundamental. Pergaminho. Patos de Minas, n.3, p. 71-88, nov., 2012.

CUNHA, R. B. O que significa alfabetização ou letramento para os pesquisadores da educação científica e qual o impacto desses conceitos no ensino de ciências. Ciência \& Educação, Bauru, v. 24, n. 1, p. 27-41, 2018.

FUMEIRO, C. L.; SILVEIRA, S. S. S.; MARTINS, S. N.; SILVA, V. J. M. O. Alfabetização científica e tecnológica como princípio da formação do cidadão. Educitec, Manaus, v. 05, n. 11, p. 150-162, jun. 2019.

GALVÃO, E. S.; NACARATO, A. M. O letramento matemático e a resolução de problemas na provinha Brasil. Revista Eletrônica de Educação, v. 7, n. 3, p. 81-96, 2013.

LOUREIRO, I. A importância da educação alimentar: o papel das escolas promotoras de saúde. Revista Portuguesa de Saúde Pública. Lisboa, vol. 22, n. 2, p. 43-55, Jul./Dez. 2004.

MARQUES, A. C. T. L.; MARANDINO, M. Alfabetização científica, criança e espaços de educação não formal: diálogos possíveis. Educação e Pesquisa, São Paulo, v. 44, e170831, 2018.

MARQUES, V.; SATRIANO, C. Narrativa autobiográfica do próprio pesquisador como fonte e ferramenta de pesquisa. Linhas Críticas, Brasília, v. 23, n. 51, jun./set., p. 369-386, 2017.

MATTOS, A. C. E.; ROCHA, L. S.; RODRIGUES, L. Dialogando sobre alimentação e nutrição na saúde mental: ações promotoras de saúde por meio de oficinas de horticultura. Revista da Associação Brasileira de Nutrição. São Paulo, SP, ano 9, n. 2, p. 17-24, Jul./Dez. 2018.

SOUZA, R. A. L; MOLL, J.; ANDRADE, F. B. Letramento acadêmico matemático dos estudantes cotistas e sua relação com o habitus. XII Encontro Nacional de Pesquisa em Educação em Ciências - XII ENPEC Universidade Federal do Rio 
NASCIMENTO, A. D.; HETKOWSKI, T. M. (Orgs.). Memória e formação de professores [online]. Salvador: EDUFBA, 2007. 310 p.

OCDE/PISA. Estrutura de avaliação PISA 2003: conhecimentos e habilidades em matemática, leitura, ciências e resolução de problemas. São Paulo, Moderna, 2004.

ROCHA, F. S. M. da; LORENZETTI, L.; KALINKE, M. A. Aproximações entre Resolução de Problemas e Modelagem Matemática com o enfoque CTS. ACTIO: Docência em Ciências, Curitiba, v. 4, n. 2, p. 109-126, mai./ago. 2019. Disponível em: https://periodicos.utfpr.edu.br/actio. Acesso em: 22 out.2019.

RUBBA, P. Integration STS into school science and teacher education: beyond awareness. Theory into Pratice, v. 30, n. 4, p. 303-15, 1991.

SANTOS, W. L. P. dos. Contextualização no ensino de ciências por meio de temas CTS em uma perspectiva crítica. Revista Ciência \& Ensino, São Paulo, vol. 1, número especial, novembro de 2007.

SANTOS, W. L. P.; MORTIMER, E. F. Tomada de decisão para a ação social responsável no ensino de ciências. Ciência \& Educação, v. 7, n. 1, p. 95-111, 2001.

SASSERON, L. H.; MACHADO, V. F. Alfabetização científica na prática: inovando a forma de ensinar física. 1a. ed. São Paulo: Editora Livraria da Física, 2017.

SELINGARDI, G.; MENEZES, M. V. M. Compreendendo o que é ser um professor reflexivo ante a ação pedagógica. ACTIO: Docência em Ciências, Curitiba, v. 2, n. 3, p. 270-286, out./dez. 2017. Disponível em:

https://periodicos.utfpr.edu.br/actio. Acesso em: 22 out. 2019.

SILVA, F. C. R.; MAIA, S. F. Narrativas autobiográficas: interfaces com a pesquisa sobre formação de professores. Disponível em:

http://leg.ufpi.br/subsiteFiles/ppged/arquivos/files/VI.encontro.2010/GT.1/GT_0 1_22.pdf. Acesso em: 18 jun. 2019.

SILVA, A. H.; TRINTIN, R. da S. Uma análise qualitativa dos conceitos básicos de Astronomia dos professores dos Anos Iniciais do Ensino Fundamental. ACTIO: Docência em Ciências, Curitiba, v. 2, n. 1, p. 304-320, jan./jul. 2017. Disponível em: https://periodicos.utfpr.edu.br/actio. Acesso em: 22 out. 2019.

SOARES, M. E.; SALES, E. R.; FRAIHA-MARTINS, F. Docência e vida em formação: fragmentos de memórias na educação inclusiva. Revista Brasileira de Pesquisa (Auto)Biográfica, Salvador, v. 03, n. 09, p. 983-997, set./dez. 2018.

THIESEN, J. S. A interdisciplinaridade como um movimento articulador no processo ensino-aprendizagem. Revista Brasileira de Educação, v. 13, n. 39, set./dez., 2008. 
Recebido: 13 ago. 2019

Aprovado: 11 nov. 2019

DOI: $10.3895 /$ actio.v4n3.10522

\section{Como citar:}

MESQUITA, A. S. de Ação social responsável: práticas de letramento científico e matemático nos anos iniciais do ensino fundamental. ACTIO, Curitiba, v. 4, n. 3, p. 309-326, set./dez. 2019. Disponível em: $<$ https://periodicos.utfpr.edu.br/actio>. Acesso em: XXX

\section{Correspondência:}

Adriano Santos de Mesquita

Alameda Belém, n. 08, Bairro: Guamá; Estado: Pará; Cidade: Belém; País: Brasil.

Direito autoral: Este artigo está licenciado sob os termos da Licença Creative Commons-Atribuição 4.0

Internacional.

(c) (1) 